\title{
Evangélicos no espaço público: show gospel, cultura e entretenimento.
}

\section{Evangelicals at public space: gospel show, culture and entertainment.}

\author{
Frank Antonio Mezzomo* \\ Cristina Satiê de Oliveira Pátaro** \\ Amanda Pinheiro***
}

Resumo: O artigo discute a presença dos evangélicos no espaço público, a partir da análise da inclusão de show gospel na Festa Nacional do Carneiro no Buraco, Campo Mourão, PR. A realização de tal programação religiosa na festa se deu pela indicação de um vereador, agente religioso vinculado à Igreja Assembleia de Deus. A partir de discussões pautadas nas noções de secularização e cultura, os resultados indicam o protagonismo do agente religioso em sua atuação no Legislativo Municipal, além da sacralização da festa cívica ocorrida com o show gospel e o momento de oração. Tal dinâmica evidencia os movimentos dos evangélicos no cenário público brasileiro, ressignificando as fronteiras entre os campos da religião e da política.

Palavras-chave: Religião. Espaço Público. Legislativo Municipal. Agente Religioso. Show Gospel.

Abstract: This paper discusses the presence of evangelicals at public space, from the analysis of inclusion a gospel show in the National Party of Lamp in the Hole, Campo Mourao, PR. The realization of such religious programming in the party was due to the appointment of a councilman, religious agent linked to the Church Assembleia de Deus. Based on discussions regarding to the notions of secularization and culture, the results indicate the protagonism of the religious agent in his performance in the Municipal Legislative, as well as the sacralization of the civic celebration from the gospel show and the moment of prayer. Such dynamics highlight the movements of

\footnotetext{
* Doutor em História Cultural. Líder do Grupo de Pesquisa Cultura e Relações de Poder e Editor da Revista NUPEM. Bolsista Produtividade em Pesquisa da Fundação Araucária/PR. Professor do Programa de Pós-Graduação Interdisciplinar Sociedade e Desenvolvimento, Universidade Estadual do Paraná (Unespar).

** Doutora em Educação. Bolsista Produtividade em Pesquisa da Fundação Araucária/PR. Professora do Programa de Pós-Graduação Interdisciplinar Sociedade e Desenvolvimento, Universidade Estadual do Paraná (Unespar).

*** Mestranda junto ao Programa de Pós-Graduação Interdisciplinar Sociedade e Desenvolvimento (PPGSeD), Universidade $\quad$ Estadual do Paraná
} Instituto Federal do Paraná (IFES/PR). 
Revista Brasileira de História \& Ciências Sociais - RBHCS

Vol. $8 \mathrm{~N}^{\mathrm{o}}$ 16, Julho - Dezembro de 2016

evangelicals in the Brazilian public scenario, re-signifying the boundaries between the fields of religion and politics.

Keywords: Religion. Public Space. Municipal Legislative. Religious Agent. Gospel Show.

Este artigo discute a presença dos evangélicos no espaço público, a partir da análise da inserção de show gospel na $23^{\circ}$ Festa Nacional do Carneiro no Buraco, realizada no ano de 2013 em Campo Mourão, estado do Paraná. A demanda surgiu por indicação de um agente religioso, integrante do legislativo municipal, e foi acolhida pelo executivo ${ }^{1}$. Nesse sentido, pretende-se problematizar os movimentos dos evangélicos em busca de protagonismo no cenário público e político, nesse caso objetivados tanto na iniciativa do referido vereador quanto na realização do show de caráter religioso em uma festa cívica.

As inter-relações entre religião e espaço público passaram a ser problematizadas, sobretudo pela Sociologia e Antropologia, por evidenciarem um fenômeno crescente, inclusive na organização política do Estado, seja nas esferas municipal, estadual ou federal. Algumas experiências desta configuração são percebidas nas aproximações entre os campos da política e da religião ocorridas no Brasil, a exemplo dos períodos eleitorais, também caracterizados como tempo da política (PALMEIRA, 2002; CERVI, 2010). A este respeito, estudos produzidos acerca das eleições proporcionais e majoritárias apontam que, nas últimas décadas, há uma forte presença de candidatos que reivindicam e afirmam sua condição de agentes ou líderes religiosos, de diversas denominações, e que, em razão do pleito eleitoral, expõem abertamente sua vinculação religiosa, tendo inclusive, em diversas situações, o apoio da instituição à sua candidatura (BURITY, 2011; ORO, 2001; MARIANO, 2005; FRESTON, 2005; MACHADO, 2006; CAMURÇA, 2008).

Diante deste contexto, as religiões evangélicas constituíram na contemporaneidade, em especial após a década de 1990, forte presença no cenário político institucional, trazendo para a esfera pública sua linguagem, seu ethos e suas demandas nas mais diversas direções (GIUMBELLI, 2012; RANQUETAT JR, 2012; BURITY, 2008; ORO, 2004). Em paralelo, os grupos evangélicos vêm igualmente conquistando legitimidade e visibilidade pela via da cultura, em especial no tocante

1 Uma primeira versão deste texto foi apresentada no $2^{\mathrm{o}}$ Simpósio Sudeste da ABHR, Gênero e religião: violência, fundamentalismo e política, São Paulo, 2015. 
às atividades de entretenimento e produções midiáticas. Dessa forma, novas configurações vão surgindo no espaço público, por meio da participação desses agentes religiosos tanto na política partidária quanto no cenário cultural, trazendo diferentes relações de poder, dinâmicas e reivindicações para a sociedade. Conforme aponta Giumbelli (2013), a maneira pela qual os evangélicos vêm atuando no cenário brasileiro, considerando o estilo e a presença pública de algumas das suas lideranças e das principais igrejas, tem favorecido para que este grupo adquira novas expressões no espaço público.

A temática aqui anunciada nos remete à problematização da noção de secularização, que, em um primeiro entendimento, é definida como o declínio da centralidade da religião enquanto instituição hegemônica da sociedade, mesmo que a considerando enquanto fenômeno social e manifestação no nível da consciência individual (ORTIZ, 2001; SANCHIS, 1995; BERGER, 1985, 2001). No entanto, ainda que tal posição não seja consensual, torna-se arriscado afirmar o declínio das práticas religiosas e da presença pública das religiões, uma vez que o movimento da secularização pode ser visto como não uniforme, reforçando-se ou rivalizando-se perante os avanços na adesão, institucionalização e pertencimento religioso (BURITY, 2008). Nesse sentido, o diálogo entre secularização, manifestação religiosa e cultura permite investigar a ressignificação e o deslocamento das fronteiras dos campos religioso e político (NOVAES, 2012; HERVIEU-LÉGER, 2008; BURITY, 2001).

Ao problematizarmos a cultura, remetemo-nos a Ortiz (2007, 2008), para quem a mesma exerce papel fundamental na articulação do mundo, pois representa um conjunto de valores, estilos e formas de pensamento comuns a uma diversidade de grupos sociais. Assim, as comunidades locais dispõem de uma força interna que, mesmo recebendo influência de culturas externas, oriundas do processo de globalização, não perdem sua identidade e sua importância perante os grupos sociais que ali residem. Ainda para o autor, a cultura refere-se ao universo do simbólico, que, por meio da linguagem, permite ao homem apreender e relacionar as coisas, de modo que não existe sociedade sem cultura. Isso porque os "universos simbólicos 'nomeiam' as coisas, relacionam as pessoas, constituem-se em visões de mundo" (ORTIZ, 2008, p. 123).

$\mathrm{Na}$ esfera da cultura, portanto, podemos perceber um movimento na reconfiguração do espaço ocupado pelo público evangélico, considerando em 
especial, no caso do presente texto, seu protagonismo na promoção e ressignificação de atividades de entretenimento. Tal movimento ganha visibilidade e proporções nacionais com o aumento de produções midiáticas e também com o investimento da indústria fonográfica de música gospel (ROSAS, 2013). Trata-se de uma expressão cultural que vem conquistando mais espaços tanto em shows como em programas de rádio e televisão.

Cunha (2004, p. 251) define como "explosão gospel” o novo estilo de culto praticado dentro de um padrão que perpassa as diferentes denominações religiosas. Seu estudo demonstrou o expressivo aumento do uso da mídia na disseminação da cultura gospel ao público evangélico. A música, em particular, merece destaque, uma vez que é a fonte mais acessada por este público, seja nas rádios, em programas televisivos, ou por meio de aquisição de CDs e DVDs.

Embora a música gospel não seja apenas destinada ao público evangélico, pois é crescente também no meio católico (SILVEIRA, 2010; CARRANZA; MARIZ, 2009), é certo que entre os primeiros tem ganhado novos fôlegos nos últimos anos, em especial após a década de 1990. A expressão da cultura gospel assenta na tríade música, consumo e entretenimento, e como produto de mercado sacraliza elementos profanos, legitima o uso de tecnologia, da diversidade de gêneros musicais, da possibilidade de consumo e do lazer (CUNHA, 2007).

As questões até aqui expostas, representativas de uma dinâmica recorrente no cenário nacional, vêm sendo problematizadas a partir de um recorte regional, com enfoque para o município de Campo Mourão, localizado na Mesorregião Centro Ocidental do Paraná. Tais investigações, conduzidas nos últimos anos² , têm buscado evidenciar as relações entre religião e espaço público, tanto nos períodos eleitorais (MEZZOMO; PÁTARO; BONINI, 2014; MEZZOMO; PÁTARO; ONOFRE, 2014; MEZZOMO; BONINI, 2013), quanto na presença pública da religião no município (MEZZOMO; BONINI, 2011; RIBEIRO; PÁTARO; MEZZOMO, 2016).

$\mathrm{Na}$ esteira de tais discussões que tematizam, na referida Mesorregião, a presença da religião no espaço público, problematizamos, para a presente discussão, a realização de um show gospel inserido na programação da $23^{\circ}$ edição da Festa

\footnotetext{
${ }^{2}$ Este trabalho está vinculado a investigação de maior abrangência intitulada "Religião e Política: participação de agentes religiosos no legislativo municipal”, sob a coordenação do professor Dr. Frank Antonio Mezzomo e com financiamento do CNPq. A pesquisa é desenvolvida junto ao Programa de Pós-Graduação Interdisciplinar Sociedade e Desenvolvimento da Universidade Estadual do Paraná (Unespar).
} 
Nacional do Carneiro no Buraco, tradicional festa do município de Campo Mourão. Tal inclusão se deu a partir da iniciativa do vereador Edilson Martins, eleito no pleito de 2012 e membro da Igreja Assembleia de Deus, mediante a Indicação n. 1.039/2013 3 encaminhada e acolhida pel o executivo municipal. Com base em tal discussão, pretende-se evidenciar que a ação do agente religioso, bem como a realização do show gospel vêm na esteira de um movimento de expansão e visibilidade dos evangélicos na esfera pública.

O material empírico da presente investigação é constituído por documentação produzida pelo vereador Edilson Martins no âmbito da Câmara Municipal de Campo Mourão, além do conteúdo disponível no site oficial da Festa Nacional do Carneiro no Buraco, mantido pela Prefeitura Municipal, onde constam notícias, fotos, programação, entrevistas e outros conteúdos relacionados à preparação e realização do show gospel. Ademais, foram ainda consultadas outras matérias e notas publicadas na imprensa local, regional e estadual, disponibilizadas via internet, que registraram a ocorrência do referido evento.

\section{O show gospel na Festa Nacional do Carneiro no Buraco}

Campo Mourão está localizado na região sul do Brasil e compõe a Mesorregião Centro Ocidental do Paraná4, a qual é constituída por uma área de 1.191,893 ha, o que corresponde a 5,96\% da área total do Estado do Paraná (IPARDES, 2004). Configurase como o maior município da Mesorregião, com uma população de mais de noventa mil habitantes, dos quais 20.720 se declaram evangélicos. Da população total aproximadamente 320 mil habitantes -58.645 pertencem a igrejas de denominação evangélica (IBGE-Cidades, 2015). A Festa Nacional do Carneiro no Buraco, realizada anualmente no município em questão, recebe o público de toda essa região, além de pessoas de outras localidades do Paraná e estados da Federação.

Figura 1: Mesorregião Centro Ocidental do Paraná

\footnotetext{
3 Indicação é um dispositivo legal utilizado pelos vereadores para apresentar suas pautas ao poder executivo, sendo em geral utilizado pelos membros do legislativo para atender a solicitações da população. Como não tem força de lei, pode ser acatado ou não pelo poder executivo (FILHO et al., 2014).

4 Os municípios que fazem parte da Mesorregião Centro-Ocidental do Paraná são: Altamira do Paraná, Araruna, Barbosa Ferraz, Boa Esperança, Campina da Lagoa, Campo Mourão, Corumbataí do Sul, Engenheiro Beltrão, Farol, Fênix, Goioerê, Iretama, Janiópolis, Juranda, Luiziana, Mamborê, Moreira Sales, Nova Cantu, Peabiru, Quarto Centenário, Quinta do Sol, Rancho Alegre D’Oeste, Roncador, Terra Boa e Ubiratã (IBGE-Cidades, 2016).
} 


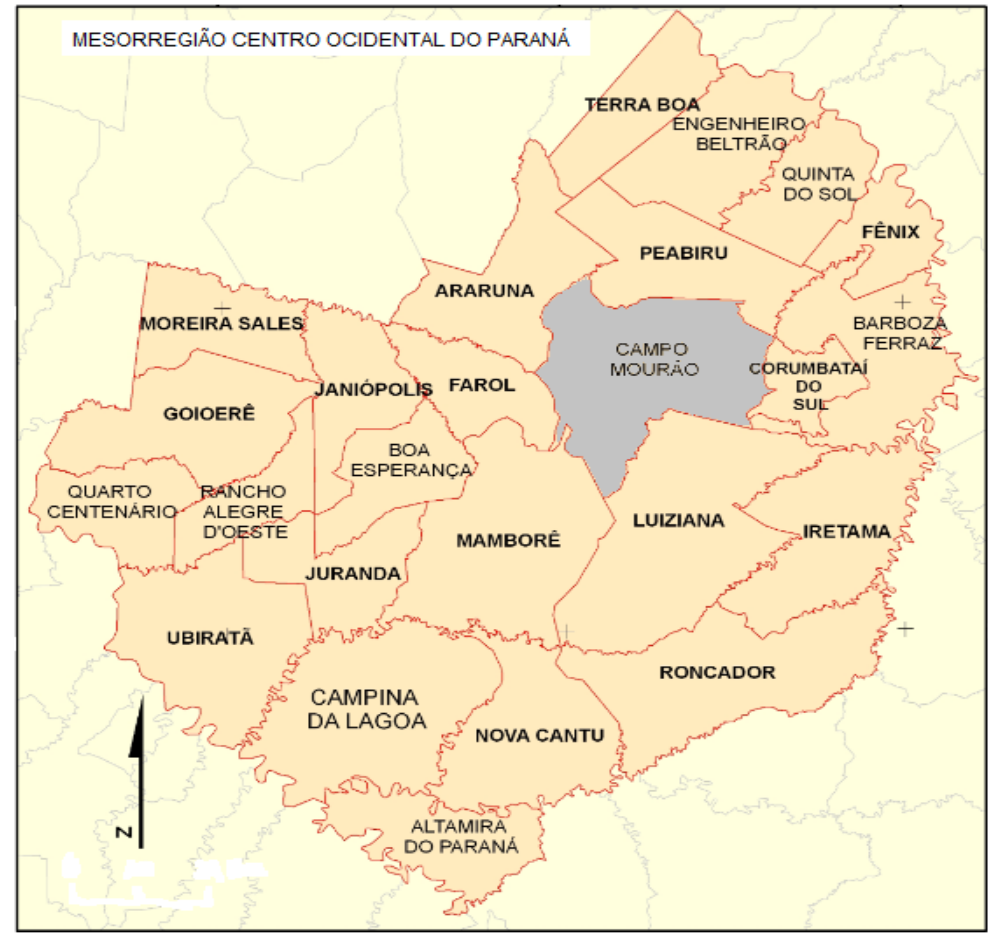

Fonte: Observatório das metrópoles, 2012 (Adaptado pela autora)

Realizada desde 1991, e oficializada como Festa Nacional do Carneiro no Buraco em 2003, o evento ocorre no mês de Julho e é organizado pelo município de Campo Mourão. Sua programação, organizada ao longo de cinco dias, envolve atividades culturais, exposições e apresentações de artistas regionais e nacionais, além do rito de preparação e organização do almoço, com o prato típico do município: o carneiro no buraco. A festa, ainda, é considerada parte integrante do patrimônio cultural de Campo Mourão, conforme Lei Municipal 2.501/2009, e representa importante movimentação na economia, além de impulsionar o turismo local e regional. A Festa Nacional do Carneiro no Buraco também representa, para o público, a maior referência da cultura local (ALVES, 2012).

A festa é caracterizada, ainda, pela recorrência ao universo simbólico, presente nos elementos míticos e rituais que envolvem o preparo do prato - o carneiro -, relacionados à representação da criação do fogo. $\mathrm{O}$ ritual conhecido como "guardião do fogo" é baseado na mitologia grega e representa a criação do céu, mar, terra e todos os elementos do universo. Reforça, também, o imaginário da chegada dos chamados pioneiros de Campo Mourão, bem como o início da construção da região, pautada no desenvolvimento agrícola e industrial. $\mathrm{O}$ encerramento do rito de preparação do prato acontece com a entrada de pessoas segurando tochas, que valorizam novamente a presença e importância do fogo para a cultura. Na sequência 


\section{Revista Brasileira de História \& Ciências Sociais - RBHCS}

Vol. $8 \mathrm{~N}^{\mathrm{o}}$ 16, Julho - Dezembro de 2016

da apresentação, o fogo é conduzido até o pavilhão onde, nos buracos que serão acesos, será realizado o cozimento da iguaria, preparada em tachos que ficam enterrados por 12 horas (MARTINS; PELEGRINI, 2014). Trata-se, portanto, de uma festa cívica, sem vínculo religioso, que busca simbolizar a cultura local, a construção da cidade, a valorização dos ditos pioneiros e também o desenvolvimento agroindustrial do município. Suas características, assim, demonstram que não há menção explícita à religião, tal como ocorre em outras festas típicas, vinculadas, por exemplo, à Igreja Católica e a Santos Padroeiros, tão comuns nos municípios do país.

Todos os anos, a programação cultural e os shows da festa são definidos e organizados pela Prefeitura Municipal. Em particular, para a edição de 2013, constou na programação oficial o primeiro show gospel, incluído em razão da Indicação 1.039/2013, de autoria do vereador Edilson Martins. A indicação foi feita no dia 01 de abril de 2013, tendo recebido parecer jurídico favorável, e sido encaminhado à Prefeita do município na semana seguinte, dia o9 de abril.

O vereador Edilson Martins é filiado ao Partido Social Democrático, tendo sido eleito para seu primeiro mandato em 2012, ocupando uma das 13 cadeiras da Câmara Municipal dos Vereadores. Obteve 1.428 votos $-2,85 \%$ dos votos válidos 5 -, eleito com a terceira maior votação do município, para o mandato que se estende de 2013 a 2016. Na ocasião das eleições, recebeu apoio dos pastores e membros da Igreja Assembleia de Deus - da qual participa desde os 13 anos -, bem como das Igrejas Presbiteriana Renovada e Brasil para Cristo (MEZZOMO; PÁTARO; ONOFRE, 2014).

Além da Indicação para a inclusão de show gospel na Festa Nacional do Carneiro no Buraco, o vereador tem, em sua atuação, apresentado outras demandas vinculadas ao campo religioso junto à Câmara Municipal, tais como: homenagens e moções a líderes religiosos, obras de infraestrutura nas imediações de templos religiosos, indicação para a instituição do Dia do Evangélico no calendário municipal, além de ter tido uma importante atuação na disputa acerca da aprovação do Plano Municipal de Educação, no intuito de excluir do texto final os termos que pudessem fazer alusão à chamada "ideologia de gênero" (RIBEIRO; PÁTARO; MEZZOMO, 2016). Vale ainda ressaltar que, no pleito eleitoral de 2016, Edilson Martins foi eleito para novo mandato junto à Câmara Municipal, tendo obtido um total de 1.293 votos.

5 Informações disponíveis em: http://www.eleicoes2012.info/edilson-martins/. Acesso em: 23/05/2016. 
Diante do exposto, podemos compreender que a atuação de Edilson Martins exemplificada neste texto pela Indicação para inclusão do show gospel na festa nacional - expressa sua condição de agente religioso (ORO, 2004), na medida em que parte de suas pautas junto à Câmara Municipal têm como uma das motivações atender às demandas de um público religioso - no caso, evangélico. Ademais, é preciso ressaltar que tais ações estão em sintonia com um movimento mais amplo de grupos evangélicos no Brasil, que vêm ampliando sua inserção na esfera pública, seja por meio de disputas políticas, de aquisição de espaço nas produções midiáticas e veículos de informação e entretenimento, ou, ainda, pela busca de benefícios financeiros mediante a isenção de impostos (CUNHA, 2007; VITAL; LOPES, 2012; ROSAS, 2013).

Para justificar a inclusão do show gospel na festa, Edilson Martins menciona que tal apresentação artística atrairia um número maior de pessoas do município e da região, conforme aponta o trecho a seguir da referida proposição:

\begin{abstract}
A presente solicitação se dá devido ao um elevado número de Cristãos (evangélicos e católicos) na cidade de Campo Mourão e considerando que atualmente nossos jovens necessitam se descolarem para Maringá e outras cidades para assistirem shows de caráter Gospel. Considerando o Censo de 2010 divulgado pelo do Instituto Brasileiro de Geografia e Estatística - IBGE, sobre a religião no Brasil, vemos que $86,8 \%$ dos brasileiros se declaram como Cristãos, e que são poucos eventos realizados para esse tipo de público. Endentemos que a realização de um Show Gospel atrairá não só o público mourãoense, mas também pessoas de várias cidades do nosso Estado (CÂMARA MUNICIPAL DE CAMPO MOURÃO, Indicação 1.039/2013).
\end{abstract}

Como se pode verificar, segundo a justificativa apresentada pelo vereador, a realização do show gospel na festa atenderia a uma expectativa da população, já que há um público cristão que não conta com atividades dessa natureza na região.

A inclusão do show gospel na Festa Nacional do Carneiro no Buraco contou ainda com o apoio do Deputado Estadual Wilson Quinteiro, também evangélico, membro da Igreja Presbiteriana Renovada, o qual teria sido eleito como representante oficial da Igreja na Assembleia Legislativa do Paraná6. Com base na análise das notícias publicadas no site oficial da Festa Nacional, Quinteiro juntamente com Edilson Martins - participou de etapas da organização do evento,

6 Informação do Blog Oficial do Deputado Wilson Quinteiro. Disponível em: http://wilsonquinteiro.blogspot.com.br/2010/o9/quinteiro-participa-de-cafe-da-manha.html. Acesso em: 6/o6/2015. 
Revista Brasileira de História \& Ciências Sociais - RBHCS

Vol. $8 \mathrm{~N}^{\mathrm{o}}$ 16, Julho - Dezembro de 2016

tendo sido ainda responsável pela contratação da Banda Filhos do Homem7, de Curitiba. O Deputado Estadual esteve também presente na abertura da programação religiosa, que contou ainda com a presença da Prefeita Municipal, bem como do viceprefeito e presidente da festa, além de outros representantes do legislativo estadual e municipal.

A inclusão do show gospel na programação da festa foi noticiada por diversas vezes tanto no site oficial quanto na imprensa local. Invariavelmente, a divulgação da atividade vinha associada ao público evangélico, e a Banda Filhos do Homem era destacada como gospel, tendo sido ainda apresentada, como um de seus objetivos, "despertar esta geração para santidade, adoração e multiplicação"8. Vale ressaltar que, na ocasião do show gospel, a banda faria, ainda, o lançamento - e comercialização - de seu novo CD. A notícia publicada um dia antes do evento destacava novamente a apresentação do grupo musical:

O público simpatizante da música gospel será privilegiado com uma atração musical amanhã (sábado), na $23^{\mathrm{a}}$ Festa Nacional do Carneiro no Buraco. Trata-se da Banda Filhos do Homem, uma banda cristã de adoração rock que já tem 17 anos de estrada, e lançará um novo CD exatamente neste evento, intitulado "Pés na Rocha" em mais uma de suas marcantes obras musicais, compostas por vários CDS e DVDS já gravados. Um dos objetivos desta formação musical, que já fez show para mais de 270 mil pessoas, é despertar esta geração para santidade, adoração e multiplicação. (Banda lança novo CD na Festa Nacional do Carneiro no Buraco, 12/07/20139).

A realização do show, ainda, foi noticiada como uma das atividades que atraiu grande público à Festa Nacional (Figura 2). A notícia publicada no site oficial em 15 de julho de 2013, dois dias após a noite da apresentação da banda gospel, tinha como título "Show Gospel atraiu evangélicos na $23^{\text {a }}$ Festa Nacional do Carneiro no Buraco"10, indicando a participação de evangélicos de diferentes igrejas. O Blog

\footnotetext{
7 A Banda Filhos do Homem, criada em 1996, realiza shows em todo o Brasil, em especial vinculados a eventos religiosos ou atividades voltadas para jovens, o que pode ser verificado na agenda de shows disponível no Portal Eletrônico da banda. No referido site, ainda constam fotos e vídeos, a discografia da banda, além de uma loja virtual para a comercialização de CDs, DVDs e livros, o que sugere seu caráter comercial. Disponível em: http://filhosdohomem.com.br/. Acesso em: 01/12/2016.

8 Informação da matéria: "Confirmados mais dois shows na Festa do Carneiro no Buraco", disponível em: http://www.campomourao.pr.gov.br/carneironoburaco/blog-single.php?not_id=1553. Acesso em: 01/12/2016.

9 Informação disponível em: http://www.campomourao.pr.gov.br/carneironoburaco/blogsingle.php? not_id=1934. Acesso em: 01/12/2016.

10 Informação disponível em: http://www.campomourao.pr.gov.br/carneironoburaco/blogsingle.php?not_id=1945. Acesso em: 01/12/2016.
} 
Revista Brasileira de História \& Ciências Sociais - RBHCS

Vol. $8 \mathrm{~N}^{\mathrm{o}}$ 16, Julho - Dezembro de 2016

Oficial do Deputado Wilson Quinteiro trazia, igualmente, que "20 mil pessoas, das mais diversas igrejas assistiram ao show"11.

Figura 2: Banda Filhos do Homem e show gospel na Festa Nacional do Carneiro no Buraco
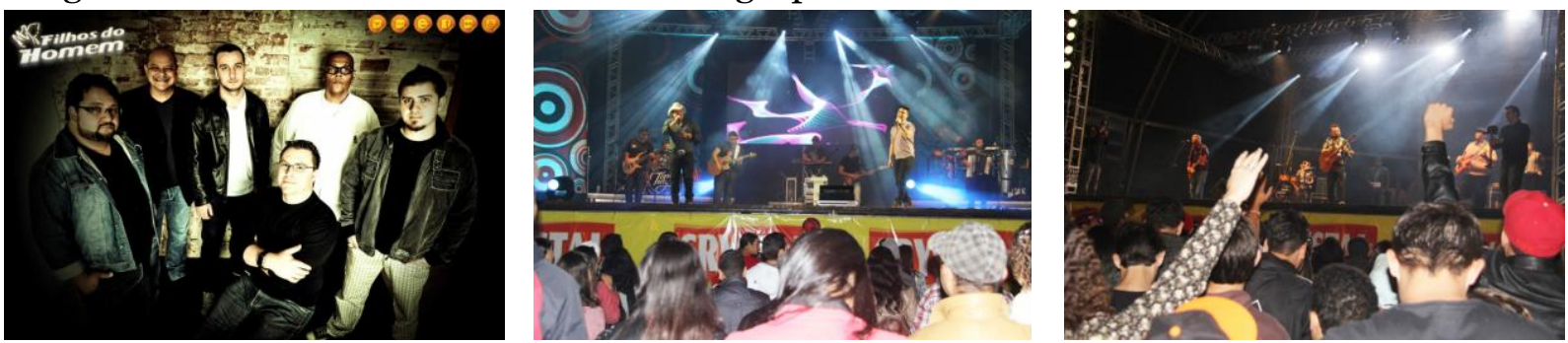

Fonte: Portal Eletrônico da Festa Nacional do Carneiro no Buraco Disponível em: http://www.campomourao.pr.gov.br/

Um ponto a ser destacado é que, na ocasião do show gospel, foi realizado um momento de oração, conduzido pelo pastor Arnildo Klumb. O referido pastor dirige a Primeira Igreja Presbiteriana de Campo Mourão, e foi eleito em 2013 como presidente da Ordem dos Pastores Evangélicos de Campo Mourão (Opecam), instituição filantrópica sem fins lucrativos, que tem como objetivo promover o congraçamento dos pastores evangélicos e suas famílias ${ }^{12}$. Fica assim evidenciado que a atração cultural, resultante da iniciativa de um agente religioso - no caso, Edilson Martins -, convergiu um momento de oração que agregou diferentes denominações evangélicas, além de entretenimento e consumo - o que confirma seu caráter gospel (CUNHA, 2007).

É possível afirmar que a realização do show gospel trouxe novos significados à noite do sábado, uma vez que criou uma oportunidade para a proclamação da palavra de Deus em espaço público. Durante os 23 anos da existência da festa, não foram identificadas outras atividades que expressassem a intenção religiosa, já que não havia, até então, apresentação gospel em sua programação ${ }^{13}$.

11 Informação do Blog Oficial do Deputado Wilson Quinteiro. Disponível em: http://wilsonquinteiro.blogspot.com.br/2013/o7/quinteiro-leva-show-gospel-para-festa.html. Acesso em: 06/06/ 2015.

12 Informação disponível em: http://www.itribuna.com.br/campo-mourao/2013/o4/pastor-arnildoklumb-assume-a-opecam/1055122/. Acesso em: 14/05/2016.

${ }^{13}$ Importante frisar que, em 2014, a programação da festa também contou com show gospel com a "Banda Átrios" e "Ministério Dimmy Oliveira", no domingo, dia 05 de julho. Tal programação foi incluída em razão de nova indicação (CMCM, indicação 07/2014) do vereador Edilson Martins, utilizando-se dos mesmos argumentos contidos na indicação feita no ano anterior. Em 2015, o vereador não propôs a inclusão deste tipo de atração na Festa Nacional do Carneiro no Buraco, e a programação da mesma não contou com show dessa natureza, fato que demonstra as implicações da iniciativa deste parlamentar em solicitar, via legislativo, a inclusão da atividade na festa realizada no município. 
A Indicação do agente religioso Edilson Martins acabou favorecendo a ocorrência de um momento de evangelização, sendo que a música e também a oração realizada sugerem o cumprimento da missão de levar a palavra de Deus ao maior número possível de pessoas, uma das características do pentecostalismo (NOVAES, 2001). Tal objetivo, inclusive, é destacado pela própria banda que conduziu o show, como apontado anteriormente.

Percebe-se, ainda, na ocasião do primeiro show gospel, a articulação entre o agente religioso municipal e um deputado estadual - Edilson Martins e Wilson Quinteiro, respectivamente -, ao levarem para a Festa Nacional a linguagem religiosa, nesse caso, por meio do show gospel, sacralizando de alguma forma o momento de entretenimento (LENHARO, 1986). Tal pauta, que atende sobretudo ao público evangélico, é introduzida pelo vereador na esfera pública, sem ter despertado controvérsias no âmbito do legislativo e do executivo municipal, uma vez que não se identificou manifestação contrária e que, inclusive, a mesma indicação se repetiu no ano seguinte. A demanda por parte do vereador Edilson Martins para a inserção de um show que exprime uma cultura religiosa e atende a um público específico significa a reafirmação de seu posicionamento enquanto representante religioso no poder público.

Desse modo, é plausível afirmar, conforme Maia, que "tenta-se ampliar o espaço sagrado para além da igreja, ou dos lares" (MAIA, 2006, p. 107). De forma análoga, Santos (2008) compreende que as ações políticas de agentes religiosos se caracterizam em algumas ocasiões enquanto extensão de ações desenvolvidas dentro das atividades eclesiais. A este respeito, vale ressaltar a utilização do espaço da festa para a oração proferida pelo Pastor Arnildo Klumb, além da música gospel em si já representar uma forma de culto - tendo em vista os objetivos da banda, de "santificação, adoração e multiplicação" -, transformando a noite do evento num momento de evangelização.

\section{Considerações finais}

O presente texto buscou evidenciar a realização de show gospel em uma festa cívica, por inciativa de um agente religioso, vereador do município de Campo Mourão. Neste percurso, a intenção foi problematizar a ocupação cada vez maior dos evangélicos no espaço público, seja pela via da política formal, seja pela esfera da cultura e do entretenimento - representado, neste artigo, pelo show gospel. 
Os resultados apresentados reforçam a ressignificação da noção de secularização no cenário contemporâneo, evidenciando que a religião não está enclausurada na esfera privada, mas vem se mantendo visível e imbricada nas disputas e na construção do espaço público, assim como exemplificado pela realização do show gospel na Festa Nacional do Carneiro no Buraco. Fatos como este corroboram para o entendimento de que "mesmo que sociedade efetivamente se apresente como secularizada e que Estado se identifique como laico, a religião permanece sendo foco de discursos, de elaborações, de delimitações" (GIUMBELLI, 2003, p. 197). Assim, o campo religioso se aproxima de outras maneiras da política, sendo uma delas pela perspectiva da cultura, a exemplo do show gospel aqui analisado.

Nesse movimento, podemos dizer que a inclusão do show gospel na Festa Nacional do Carneiro no Buraco de Campo Mourão, Paraná, aponta para uma dentre as várias formas de manifestações de evangélicos na sociedade brasileira, por meio de expressões relacionadas à "cultura pública" (GIUMBELLI, 2013). Neste caso, o termo "cultura", segundo o autor, remete mais a algo a ser constituído do que a algo já estabelecido - como no caso da "cultura nacional", relacionada ao catolicismo, ou da "cultura étnica", vinculada às religiões afro-brasileiras. Isso decorre do interesse dos evangélicos em ampliar e garantir sua visibilidade, buscando, para tanto, sua inserção em diversos espaços públicos, tais como os shows de música gospel. Neste sentido, segundo o autor, "No se desea llegar a la sociedad en su totalidad, sino llegar a muchas de sus diversas partes, a través de acciones que buscan tanto la ocupación de posiciones, como la proliferación de referencias" (GIUMBELLI, 2013, p. 21). A música gospel, assim, tem favorecido uma nova forma de relação entre religião e espaço público, possibilitando sua inserção, por exemplo, em festas cívicas.

Além disso, atentamos para o fato de que a realização do show na programação oficial da Festa Nacional se deu por meio de um expediente do legislativo, que consistiu na indicação de um vereador agente religioso. Nesse sentido, destacamos que a esfera da política institucional tem servido igualmente como uma das vias de proposição e legitimação das demandas afetas aos grupos evangélicos no cenário público.

Por fim, cabe destacar que a atuação do agente religioso, bem como a realização do show gospel na festa cívica não podem ser tomados como episódios isolados e excepcionais, visto que se somam a outros movimentos no cenário 
nacional, que indicam a presença cada vez maior de pautas e agentes religiosos - em especial evangélicos - na esfera pública, justificando, portanto, a realização de discussões acerca de novos sujeitos, grupos e demandas nas disputas e nas relações de poder que passam a reconfigurar o cenário social.

\section{Referências}

ALVES, Larissa de Mattos. Geografia e o Poder Local: Relações entre os hoteleiros, o poder público municipal e as entidades representativas em Campo Mourão. Dissertação (Mestrado em Geografia) - Universidade Estadual de Maringá. Maringá, 2012.

BERGER. Peter. O dossel sagrado: elementos para uma teoria sociológica da religião. São Paulo: Paulus, 1985.

- A dessecularização do mundo: uma visão global. Revista Religião e Sociedade, Rio de Janeiro, v. 21, n. 1, p. 9-24, abril. 2001.

BURITY, Joanildo. Fé na revolução: Protestantismo e o discurso revolucionário brasileiro (1961-1964). Rio de Janeiro: Novos Diálogos, 2011.

p. 83-113, 2008.

. Religião, política e cultura. Revista Tempo Social, São Paulo, v. 20, n. 2,

. Religião e política na fronteira: desistitucionalização e deslocamento numa relação historicamente polêmica. Revista Estudos de Religião, São Paulo, v. 4, n. 4, p. 27-45, 2001.

CAMPO MOURÃO. Lei 2.501, de 26 de outubro de 2009. Declara o prato típico Carneiro no Buraco como patrimônio cultural de Campo Mourão. Paço Municipal. Campo Mourão. 26 de outubro de 2009.

CAMURÇA, Marcelo Ayres. Ciências Sociais e Ciências da Religião: polêmicas e interlocuções. São Paulo: Paulinas, 2008.

CARRANZA, Brenda; MARIZ, Cecília (Org.). Novas comunidades católicas: em busca do espaço pós-moderno. Aparecida: Idéias \& Letras, 2009.

CERVI, Emerson Urizzi. O "tempo da política" e a distribuição dos recursos partidários: uma análise do HGPE. Em Debate, Belo Horizonte, v. 2, n. 8, p. 12-17, ago. 2010.

CUNHA, Magali do Nascimento. A explosão Gospel: Um olhar das ciências humanas sobre o cenário evangélico no Brasil. Rio de Janeiro: Mauad, 2007.

. "Vinho novo em odres velhos". Um olhar comunicacional sobre a explosão gospel no cenário religioso evangélico no Brasil. Tese (Doutorado em Comunicação e Artes) - Universidade de São Paulo. São Paulo, 2004. 
FILHO, Paulo M. D’Ávila; LIMA, Paulo Cesar G. de Cerqueira; JORGE, Vladimyr Lombardo. Indicação e intermediação de interesses: uma análise da conexão eleitoral na cidade do Rio de Janeiro, 2001-2004. Revista de Sociologia e Política, Curitiba v. 22, n. 49, p. 39-60, mar. 2014.

FRESTON, Paul. The UniversalChurch of the Kingdom of God: A BrazilianChurch Finds Sucess in Southern Africa. Jornal of Religion in Africa, v. 35, p. 33-65, 2005 .

GIUMBELLI, Emerson. Cultura Pública: evangélicos y su presencia en la sociedad brasileña. Sociedad y Religión, v. 23, p. 13-43, 2013.

. Crucifixos em recintos estatais e monumento do Cristo Redentor: distintas relações entre símbolos religiosos e espaços públicos. In: ORO, Ari Pedro; STEIL, Carlos Alberto; CIPRIANI, Roberto; GIUMBELLI, Emerson (Org.). A religião no espaço público: atores e objetos. São Paulo: Terceiro Nome, 2012.

. O chute na santa: blasfêmia e pluralismo religioso no Brasil. In: BIRMAN, P. (Org.). Religião e espaço público. São Paulo: Attar, 2003, p. 169-199.

HERVIEU-LÉGER, Danièle. O Peregrino e o convertido: a religião em movimento. Petrópolis: Vozes, 2008.

INSTITUTO BRASILEIRO DE GEOGRAFIA E ESTATÍSTICA - Cidades. Disponível em: http://cidades.ibge.gov.br. Acesso em: 10/05/2016.

Censo demográfico 2010. Disponível em: http://www.ibge.gov.br/home/estatistica/populacao/censo2010/caracteristicas_reli giao_deficiencia/default_caracteristicas_religiao_deficiencia.shtm. Acesso em: 5/05/2016.

INSTITUTO PARANAENSE DE DESENVOLVIMENTO ECONÔMICO E SOCIAL IPARDES. Disponível em:

http://www.ipardes.gov.br/pdf/mapas/base_fisica/relacao_mun_micros_mesos_pa rana.pdf. Acesso em: 5/05/2016.

LENHARO, Alcir. Sacralização da política. Campinas: Papirus, 1986.

MACHADO, Maria das Dores. Política e Religião: a participação dos evangélicos nas eleições. Rio de Janeiro: FGV, 2006.

MAIA, Eduardo Lopes Cabral. Os evangélicos e a política. Revista Em Tese, Florianópolis, v. 2, n. 2 (4), p. 91-112, ago./dez. 2006.

MARIANO, Ricardo. Neopentecostais: sociologia do novo pentecostalismo no Brasil. São Paulo: Edições Loyola, 2005.

MARTINS, Bruna Morante Lacerda; PELEGRINI, Sandra de Cássia Araújo. A celebração do 'Carneiro no Buraco' e os 'Rituais do Fogo' em Campo Mourão - PR. In: XIV Encontro Regional de História, 2014, Campo Mourão. Anais do XIV Encontro Regional de História: 1964 - 2014: 50 anos do golpe militar no Brasil, 2014. 
MEZZOMO, Frank Antonio; PÁTARO, Cristina Satiê de Oliveira; BONINI, Lara de Fátima Grigoletto. Religião e política nas eleições o legislativo municipal de Campo Mourão/PR. Debates do NER, Porto Alegre, v.1, n.25, p. 271-289, 2014.

MEZZOMO, Frank Antonio; PÁTARO, Cristina Satiê de Oliveira; ONOFRE, Lucas. Evangélicos na política: as eleições proporcionais de Campo Mourão em 2012. Revista de Estudos da Religião, São Paulo, v. 14, n. 2, jul./dez., p. 244-264, 2014.

MEZZOMO, Frank Antonio; BONINI, Lara de Fátima Grigoletto. Política e religião no regime militar: posicionamentos do legislativo municipal de Campo Mourão/PR (1973-1982). Esboços, v. 20, p. 140-157, 2013.

. O religioso em contexto político-eleitoral: eleições proporcionais de Campo Mourão/PR. Revista Brasileira de História das Religiões, Maringá, v. 4, p. 183-204, 2011.

NOVAES, Regina. Juventude, religião e espaço público: exemplos "bons para pensar" tempos e sinais. Religião e Sociedade, Rio de Janeiro, v. 31, n. 1, p. 184-208, 2012.

. A divina política Notas sobre as relações delicadas entre religião e política. Revista USP, São Paulo, n. 49, p. 60-81, mar/maio, 2001.

OBERVATÓRIO DAS METRÓPOLES. Disponível em: www.observatoriodasmetropoles.net/download/relatorio_comcam.pdf. Acesso em: 30/09/2015.

ORO, Ari Pedro. Religiões e Eleições em Porto Alegre. Um comparativo entre 2000 e 2004. Debates do NER, Porto Alegre, ano 5, n. 6, p. 9-34, 2004.

. Religião e política nas eleições 2000 em Porto Alegre. Debates do NER, Porto Alegre, ano 2, n. 3, p. 9-70, 2001.

ORTIZ, Renato. Cultura e Desenvolvimento. Políticas Culturais em Revista, Bahia, v. 1, n. 1, p. 122-128, 2008.

Mundialização e cultura. São Paulo: Braziliense, 2007.

PALMEIRA, Moacir. Política e tempo: nota exploratória. In: PEIRANO, Mariza (Org.). $O$ dito e o feito: ensaios de antropologia dos rituais. Rio de Janeiro: Relume Dumará, 2002, p. 171-178.

RANQUETAT JUNIOR, Cesar Alberto. A presença da Bíblia e do crucifixo em espaços públicos no Brasil: religião, cultura e nação. ORO, Ari Pedro; STEIL, Carlos Alberto; CIPRIANI, Roberto; GIUMBELLI, Emerson (Org.). A religião no espaço público: atores e objetos. São Paulo: Terceiro Nome, 2012, p 61-79.

RIBEIRO, Amanda de Souza; PÁTARO, Cristina Satiê de Oliveira; MEZZOMO, Frank Antonio. Religião e "ideologia de gênero" no Plano Nacional de Educação. Relegens Thréskeia, Curitiba, v. 5, n. 2, 2016. 
ROSAS, Nina. Religião, mídia e produção fonográfica: O Diante do Trono e as disputas com a Igreja Universal. Religião e Sociedade, Rio de Janeiro, v. 33, n. 1, p. 167-194, 2013.

SANCHIS, Pierre. O campo religioso será ainda hoje o campo das religiões? In: HOORNAERT, Eduardo (Org.). História da Igreja na América Latina e no Caribe (1945-1995): o debate metodológico. Petrópolis: Vozes, 1995.

SANTOS, Márcio Martins dos. “Tribunos do povo, servos de Deus”. Um estudo antropológico sobre políticos e religião na cidade de Porto Alegre. Revista ANTHROPOLÓGICAS, ano 12, v. 19, p. 201-239, 2008.

SILVEIRA, Emerson Sena. Atores religiosos populares e midiático-consumismo católico. Plura: Revista de Estudos de Religião, v. 1, n. 1, p. 178-201, 2010.

VITAL, Christina; LOPES, Paulo Victor Leite. Religião e Política: uma análise da atuação de parlamentares evangélicos sobre direitos das mulheres e de LGBTs no Brasil. Rio de Janeiro: Fundação Heinrich Böll/ISER, 2012. 